\title{
SECURITY PSYCHOLOGY AS SOCIAL SYSTEMIC PHENOMENON
}

\begin{abstract}
Yuri P.Zinchenko
Lomonosov Moscow State University

Moscow

Security psychology is considered through social systemic search for reciprocal contiguity and mutual completion of existing advances of psychology and conceptual security understanding. The ability of systemic vision of security and its cognitive and practical specifics are demonstrated. The possibility to investigate safety psychology as social theoretical construct is suggested. Multi-aspect approach to security is substantiated. Methodological challenges of psychological security are discussed.
\end{abstract}

Key words: security, systems approach, social representation, social theoretical construct, security concept, social and psychological fundamentals of security.

Analysis of domestic and foreign literature has demonstrated that the problem of security psychology, a fully-formed field of scientific analysis, as well as a prior scientific and practical task has never been considered in its entirety.

Security is a complicated social phenomenon, which is multisided and multi-approachable in its structural components and expressions showing contradictory interests of different social subjects. Opposition analysis marked as "danger - security" necessitates a wider synthesis of humanity knowledge, within which the given category is considered as the fundamental one.

A separate individual, a group of people or a society, acting in different roles, can be both the subject and the object of security psychology. An individual can be considered both as a personality and a member of a certain group or the society as a whole. Social medium as a subject of security psychology realizes security for an individual, a group or a collective security tasks in structure-functional formats.

"Security scene is a scene of role improvisations. There are only three actors there: a human being, the society and the state. Truth be told, a 
human being has two sides of his presence: he acts both as an individual personality, and a collective, a certain social group (age, dwelling, ethnical, professional etc) which is included in a united society or divided into two or more social entities. Likewise, an actor which is the state is 'multiplied' into a community of states in several scene episodes. Every actor can speak out his lines in two ways of how they are originally written (in active or passive voice) or act two roles at the same time - of a security subject and a security object. He is given two opportunities as he is both the artist and the clay, Pygmalion and Galatea. His real role for every given moment, the opportunity he jumps into and the opportunities laid aside is determined not only by himself, but also by the other actors" (Y.V. Fenenko).

Nowadays there's a sound possibility of considering security psychology problem via social and systematic search of reciprocal completion and overlapping of the existing achievements of the present psychology and conceptual vision of security in information, military, international, ethnical and corporate fields of knowledge.

Studying of security as a system is closely connected with the theory of continual link between personality and security of the society. Systematic vision of security opens room for studying of regularities of development and functioning of a human being as an element living the life of the whole system.

With the help of systematic approach mechanisms of functioning of psychic phenomena, as well as the mechanisms defining dynamics and direction of psychic development, can be described. Self-regulation and self-organization systems, as well as the system of structuring of subjective experience, are the key important among the others here included, as they define active, constructive and goal-oriented human everyday life position, together with determining the perspectives and the fundamentals of psychological security of personality.

The notion of security, being abstract enough, saturates itself with new contents as it gets involved into new connections and realizations. The path from being an abstract single-way defined notion to becoming a solid term is done grace to systematic characteristics meaningful for this informative field. This is reflected in a range of concrete actions of a personality towards a group of a social entity in the variety of their expressions and directions.

The field of theoretical researches and practical applications for the security psychology is formed as integrity of a number of different psy- 
chological and non-psychological scientific and humanity disciplines, among which are: general and social psychology, labor psychology, pedagogical psychology, development psychology and psychology of general security, sociology, psychiatry, medicine etc. Fully diversified inter-disciplinary approach is the only possible for full recognition of the given problem.

The new methodological analysis would require new understanding of the tasks here defined as follows: building of the entire theory of security psychology based on the all-sided analysis done in its social representation, functional reality, motivation and consumer orientation and reflectivity over values and socio-behavioral norms.

As a matter of fact, a human being learns the world around via social representations and he interprets social reality accordingly. Self-perception, when a person is secure or in danger, leads to building of a certain world vision in which a human being lives and acts. The building of lifemeaningful orientation, organization of information about the world around into a certain system reflecting social cognition and its dominating values depend largely on specifics of inner world constructing and world perception done through the prism of security/danger.

One of the psychological needs of a human being in the contemporary world is the need in security. It occurs in early childhood and persists throughout the whole life of a person. Providing of security is a social experience which is among the top important ones for a human being. It is the need in security which urges a person to constantly rethink social occurrences around, as well as to search for adequate ways of overcoming of the continuously appearing threats to both physical and spiritual existence.

Security conditioning affects the hierarchy of values as well. In the transition period of the Russian society a cordial change of values, coupled with full opposition of attitudes to "old" and "new" values can be seen. The mass conscious proves yet unformed for multi-dimensional world vision, and the "narrowing", which is non-perceptive "blindness" towards a number of general social values coupled with mass deformation of spiritual values, occurs.

Security psychology is the only scientific psychological discipline which unifies achievements of methodologies and methods of a number of fields of psychological science into a universal set of definitions. Security as a psychological problem has a very complicated structure, an 
integrity of various fields of activities in social relations, which bears no gaps, i.e. all the aspects of the multifunctional problem of security providing must be interrelated and interconnected.

A multitude of representations of security psychology as a science and the field of practical knowledge is the original for complication in defining of this subject. This task can be solved if various approaches and theoretical understanding of the following heterogeneous reflective tasks are integrated:

- the problems of psychological security on the individual level of human existence;

- the problems of psychological security on the level of minor and major groups

- the problems of psychological security on the level of society functioning and existing.

The semantic format of the hypothesis covering social essence and structural-functional components of security psychology in their effectiveness in social reality should be specially noted. Achievement of security derives from meaning-generating capacities of the subject forced to overcome crisis or extreme situations. It is personality essences, being a "kernel of the personality", that can be considered to be a fundamental factor of security formation.

It is also important to note, that a human being continuously tries to expand the available limits of security, enrich its essence. Both negative and positive aims are localized in certain areas of living of the subject, thus approaching certain aspects and kinds of security. The choice of angle or the criterion of classification is also important: it is influential for aspects/kinds of security which unify, dismantle, reconfigure or even overlap.

Cognitive-practical feature of the security psychology problem setting should be paid special attention to. The analysis of human security providing problems from the perspective of psychology endorses new tasks, which are: striving to safeguard of the psychological and physical health, strengthening of psychological stamina, adequacy of attitude and overall relation to the world, and finally security of psycho and consciousness against unwilling changes.

Obvious impossibility to secure a person against all the dangers, threats and crisis conditions ushered by the progress leads to necessity of 
rethinking of security in its current understanding. The real need in scientific description of the security phenomenon as a part of psychological studies has made itself seen.

Principal insufficiency of scientific and practical material as the subject of studies caused by constant actualization of the object on individual, group and socio-institutional level is also important to take to account. "Full security such as the one in the times of first people being born is absolutely unattainable as since that a choice between good and bad should always be made, despite their correct identification is difficult enough in every given time" (Bekhman, 2007, p. 27).

There is no final stage of security, which means there is no drawing the line to mark absolute security. The situation previously conceived of as dangerous for people, can now become a quite usual one. The factor of social tiredness in the society and its adaptation to danger should also be considered. With certain time elapsed, the danger can be viewed as a no longer real, but hypothetical. Thus, according to L. Gudkov, the director of Levada-center, Russian people have almost fully adopted to terrorist attacks. Almost half of the poll recipients (48\%) are to some extent sure the terrorist attacks have become "usual circumstances of our lives". This means a terrorist attack for the Russian "has become a routine and an event expected to happed, it is no longer perceived as an extraordinary happening" (Khamrayev, 2011, p. 4).

The situation of instability proves a wide platform for various psychological processes to occur, which helps blurring of the social categories, especially in relation to such an obscure one as security. Radical transformations in the society have become an habitual part of life, providing constant changes in the attitude to criteria and forms of secure life, their importance estimates changing to the opposite to ones actual in the initial stages of these changes.

An opportunity of security psychology research as socio-theoretical construct enables to create a new concept of security, with its main idea in the progress affecting the lives of people and guaranteeing basic freedoms of personality and ensuring its security and well-being as well as decent level of society development as a whole. Encouragement, respect and defending of human rights are closely connected to personality security providing. Humanity problems, apart from other important issues topical for the world society, need integral approach when being resolved, as this is the most optimal way of providing security in 
XXI century, with its conditions of general vulnerability and interdependence, given that the very notion of "security" has not only been enhanced, but also acquired more humanity-demanded and humanoriented qualities.

Security psychology should be considered as a general notion of social learning, an existing notion of life-meaning orientation, a value notion of individual conscious, and an interactive notion of self-regulation and self-sufficiency processes.

Genuine learning of the world around is also endorsed by self-interpretation, i.e. individual's interpretation of his own experiences in the key terms of own semantic context. The genuine understanding can only exist under conditions of active operating of postulate about different self, which is conscious and structurally analogous to the individual's self-consciousness. Interpretation defines the format of human realization of his security, which largely depends on his understanding and his own semantics of security conditions.

Thus, security conditions form models of human behavior and depend on self-regulation and self-sufficiency potency. Self-regulation as a security providing mechanism reveals personality ways of control over satiation appropriate to objective and subjective conditions of activities. A decision-making mechanism is presented as the mechanism of control, activation and climax.

One of the regularities of psychological self-sufficiency is that biosocial organization of a human being both facilitates and interferes with self-providing of security. As a result, the subject is characterized by a certain safety factor, and, consequently, a security potential. Timely discovering and identification of dangers and adequate reaction on them are provided by cognitive, emotional, will and motivational and consumatory characteristics of a subject. It is them that enable constant display of danger signals, an individual's time limit capacities to react on these signals, his emotional reactions to dangers etc. Together with this, there are also weaknesses of the above mentioned psychological spheres bringing down the subject's capacities of security self-providing. In the field of emotions, it is destructive influence of a wide range of asthenic emotions or fit of passion; in the field of will these are complications of willing decision and in motivational sphere it is motives' conflict. In the cognitive sphere these are the specifics of perception, memory limitation, specifics of thinking processes and in the communicative field 
these are mutual understanding drawbacks, falters in interpretation adequacy etc. These can considerably shatter the stability of the subject's psychological state within the framework of actualization of the threat to his security.

Social essence of security psychology is determination of security conditions and their integral empirical, practical and reflexive representation. Success in mastering and adequate choice-making of the way of its adaptation depends on interrelation between the real and the subjective world.

The idea of security in the common conscious is blurred enough, given security itself is seldom to become a subject of special deepen reflection. People are more likely to feel rather than to clearly understand what is security for them, as they percept and estimate it in the total of all its sides, singling out none of them. They often materialize their own senses and estimates not in the notion of "security" as such, but in a certain image, which, however meaningful, still lacks reflection of the wanted condition of security.

Multi-aspect approach to security enables to consider security as a condition, which provides fundamental securitization of personality and makes it possible to consider personality security condition as a social and normative ideal. Personality, being in the conditions of security, is capable of building its life in the context of unification with the reality around, and can use its potential with help of a formed system of semantic regulation, as well as an ability to maintain its health through transformation of dangers.

In the conditions of changing world a person needs to demonstrate a special skill to realize effective and constant orienteering in the dimensions of social reality. Any life activity of the subject is done in the context of a certain situation. A person has to constantly make decisions in the new constantly changing conditions within the current situation and in order to provide self-security.

Generalization and synthesis of above mentioned approaches aimed at defining of integrative angle of psychological capacities of a human providing his security is one of the perspective tasks of psychological security of personality. Search and development of diagnostic instruments which change the given angle, defining of age, gender or professional specifics affecting psychological aspects of security of a human are important enough tasks as well. 
Thus, the main methodological task set before security psychology is as follows:

- accuracy of ways and mechanisms of social learning for studying of objective realities and dangers for security of both personality and society;

- analytical quality, which is seen in the scientific interpretation of the very notion of "security" as a part of psychological "thesaurus";

- all-sidedness, which implies the necessity of full covering of issues concerning security, as well as understanding of security as a socio-systemic phenomenon, considering its dimensionality and hierarchism.

Security has socio-psychological fundamentals, as it functions and is represented in the system of social relations of personality, in interpersonal interaction and communication with other people. Social environment influences personal perception of its own psychological security with the help of socio-psychological adaptation processes.

The concept of psychological security adheres to multitude of precise zones of security, such as security of personality, security of a group and security of a society. They in their turn include the following aspects: security of motivation and consumatory sphere, values and regulators of human behavior, security of communication sphere, security of affective and motivation sphere of a personality etc., which are not arranged in the sound hierarchy of the most important, important and not important aspects. They are arranged in a unified chain. It is unchanged, and it has one or the other aspect of security which is most interesting for one or the other empirical zone of security, standing out on the first place under the influence of situational changes. The interest of empirical zones (or levels) attaches primary importance to this aspect in the given place and the given time only. In the case of competing securities situation, the most threatened aspect and the most vulnerable aspect of security, need to be found. It is them that need efforts of empirical zones, focused on security providing, concentrated. The objects which experience the biggest threat of security loss, must take place of the most active and energetic subjects of threat elimination.

In conclusion it should be noted, that research of security as a sociosystemic phenomenon is increasingly topical in the age of globalization, 
when specific problems of providing of separate kinds of security are rightfully replaced by the total of interconnected factors, which generally provide favorable conditions for safe development of the contemporary world.

\section{References}

Bekhman, G. (2007). Sovremennoe obshcestvo kak obshcestvo riska [Modern society as risk society]. Issue of philosophy, 1, 26-46.

Fenenko, Y.V. Bezopasnost' lichnosti kak nauchnaja problema [Security of personality as scientific issue] In Non-profit oriented partnership "Scientific wire agency 'DOMESTIC HERITAGE'”. URL: http://viperson.ru/

Khamrayev, V. (2011). Terakty otchuzhdajut Severnyj Kavkaz: Massovoe soznanie ne osvobozhdaetsja ot ksenofobii [Terrorist attacks alienate Borth Caucasus: Mass conscious is not clear of xenophobia]. Kommersant Daily, 19 (4560), 4. (04.02.2011). 